\title{
MODELING WAYS TO IMPROVE GREEN GROWTH AND ENVIRONMENTAL PROTECTION IN THE CONTEXT OF GOVERNANCE
}

\author{
Iulii PYLIAVSKYI® ${ }^{*}$, Halyna PUSHAK (D)2 Oleksandr MOLNAR (D) 3 , \\ Halyna DZYANA ${ }^{1}{ }^{4}$, Volodymyr KUSHNIRIUK (D5 \\ ${ }^{1,}{ }^{3}$ Department of Economic Theory, Uzhhorod National University, Uzhhorod, Ukraine \\ ${ }^{2}$ Department of Theoretical and Applied Economics, Lviv Polytechnic National University, Lviv, Ukraine \\ ${ }^{4}$ Department of Public Administration of Lviv Regional Institute for Public Administration of the National \\ Academy for Public Administration, Lviv, Ukraine \\ ${ }^{5}$ Department of Public Administration, Ivano-Frankivsk National Technical University of Oil and Gas, \\ Ivano-Frankivsk, Ukraine
}

Received 22 May 2020; accepted 31 December 2020

\section{Highlights}

- The formation of principles for improving green growth in the context of public administration is a powerful lever for the development of the country.

- Using functional modeling methodology and a graphical description of the processes makes it possible to systematize the goal.

- The methodology for improving green growth was introduced in the context of optimizing the management of natural resources and landscape objects at the state and regional levels; it turned out to be effective in the structural units of government bodies of countries such as Poland and Ukraine.

\begin{abstract}
In recent years, the idea of green growth has been widely discussed not only by experts in environmental economics, but also in various political forums. Many countries use various tools and principles of green growth in their national policies and growth strategies. However, some countries fear that the transition to a green growth model may hamper their development. The article discusses the prerequisites for implementation, the basic principles of green growth into the system of public administration, and also provides a system for modelling ways to implement the principles of green growth using the IDEF0 (functional modeling methodology and a graphical description of the processes) methodology. This methodology allows to clearly see the ways and means of achieving this goal. Considering the importance of the economic component in all processes of monitoring, control and protection of air, water and soil from pollution processes, a system for modeling ways to implement the principles of green growth using the IDEF0 methodology has been formed today is especially relevant.
\end{abstract}

Keywords: green growth, model, environment, methodology, public administration, environmental protection.

\section{Introduction}

Over the past three decades, humanity has made significant progress in improving material well-being. But this progress was taken at the cost of the degradation of the planet's natural environment. Continuing economic development without fundamentally changing the current economic model will lead to an increase in environmental threats and make sustainable development impossible (Sharifi et al., 2020). Despite this, economists, sociologists, politicians, representatives of natural sciences and business began to search for new ways of development, which made it possible to restore the natural environment and at the same time ensure a decent standard of living for the population. One of the results of such a search was the concept of a "green" economy, thanks to the support of international organizations and national governments, has gained significant popularity (Wellmann et al., 2020).

The spread of "green" ideas led to a "boom" of scientific and applied publications, but in them scientists have

*Corresponding author. E-mail: oli2727@yahoo.com 
not yet formulated a single established view of the content of the concept of "green" economy, its essential features, criteria and principles of construction. The foregoing necessitates the development of scientific foundations for the study of "green" growth in the context of sustainable economic development (Alrasheedi et al., 2020).

Sustainable development and green growth requires new ideas for its implementation. Today it is obvious that for the survival and development of mankind, a transition to a new economic model of development is needed. Such a model is recognized as a model of the of "green growth" economy. Sustainable development remains the most important long-term goal, but to achieve it, the economy needs to be made green. The sustainable development model provides for a comprehensive relationship between the three components of development: economic, social and environmental. The concept of environmental economic growth is designed to provide a more harmonization of these three components, which would be acceptable to all countries of the world, regardless of level of development (Postuła \& Radecka-Moroz, 2020).

Without the introduction of fundamentally new approaches to the formation of social development strategies, it is impossible to offer a way out of the current situation of a complex crisis at the global level of a dangerous combination of fuel and food, financial and climate crises. Collectively, global crises deepen pressing socio-economic problems related to job cuts, social insecurity and poverty. Preserving the "polluting" economy with its traditional dependence on non-renewable energy sources, wasteful use of material resources, high climate risks and investing in unstable sectors of the economy will reproduce the same imbalances and make permanent to those global crises that humanity is facing today. The transition to the principles of "green growth" and a reduction in investment in fossil fuels and other "polluting" sectors while increasing investments in renewable energy, energy conservation, public transport, sustainable agriculture, the protection and rational use of land and water resources will allow providing a solution to these problems.

The concept of green growth is based on the assumption that economic and environmental policies can stimulate green growth and increase carbon, energy and material efficiency while preserving natural assets and improving people's quality of life (Deschenes, 2010).

Green growth means stimulating economic growth and development, while ensuring the preservation of natural assets and the uninterrupted supply of resources and ecosystem services on which our well-being depends. To do this, it must catalyse investment and innovation, which will form the basis of sustainable growth and lead to new economic opportunities.

Green growth is a model of the economy that improves human well-being and social justice while significantly reducing environmental risks and scarcity of environmental resources. The transition to a green economy depends on solving two related tasks to maintain the sustainability of ecosystems and identify ways to reduce the use of resources in production and consumption, as well as to reduce their impact on the environment (Artene et al., 2020).

Responding to the challenge of time, a number of countries have embarked on greening the economy, which requires improving production processes and creating new, more efficient products, stimulating innovation and structural changes in the economy, creating conditions for financial consolidation by reviewing the composition and effectiveness of public spending and increasing revenue by increasing pollution charges, strengthening investor confidence through greater predictability and stability, creating a more balanced macroeconomic conditions and stable prices for natural resources. Developing effective policies to support green growth requires reliable information that reflects the relationship between the economy and the environment. Monitoring processes and assessing progress in relation to green growth not only contribute to a better understanding of the factors that determine it, but also point to the possibility of synergies in relation to interrelated economic and environmental goals. A correct idea of the country's natural assets and existing economic opportunities, monitoring of environmental aspects of the quality of life contribute to the identification of priorities of state policy. Reliable data is also needed to inform the public about progress in green growth.

The concept of environmental growth is gaining increasing public resonance. It is actively discussed by scientists, experts, politicians, non-governmental organizations. The term "green growth" was first used by a group of scientists from the London Center for Environmental Economics (LEEC) D. Pierce, A. Markandyan, E. Barbier in the report of the British government "Project Green Economy". Although it should be recognized that various aspects of the environmental problem and the possibilities of its solution were raised by scientists much earlier (Arrow et al., 2012).

In 1992, the United Nations Conference on Environment and Development, known as the Earth Summit, was held in Rio de Janeiro to mark the new vector of human movement. The Earth Summit highlighted the principles of sustainable development to improve social security and the economic systems that they support, as well as environmental development issues at the international level. Its main results were the adoption of the following documents: Agenda 21, the Declaration on Environment and Development, the Principles of Forestry and two conventions: the UN Framework Convention on Climate Change and the Convention on Biological Diversity. These documents have shaped and guided sustainable development strategies and programs at the international, regional, national and local levels for two decades. The program plan was aimed at achieving two goals - a high quality environment and healthy environmental growth for all peoples of the world.

A green growth theory does not favor any one political theory. It is possible in any economy, state or market, is 
not an alternative to sustainable development. Rather, it is a way of pursuing a course towards such development at the national, regional and world levels and in ways.

\section{Theoretical framework}

\subsection{Literature review}

Issues of the development of green growth principles in the context of public administration have begun to be studied recently. The initial impetus to these studies was the global awareness of the importance of implementing the principles of greening at all levels of the state administration apparatus.

The highest goal of global civilization, according to Khutorova (2019), is today the creation of an extra-national citizen of a single world state, which will be characterized by special mobility to harsh changes in living conditions, professions, and cultural environment. To this, in light of the existing environmental contradictions, it is justifiable to add a responsible attitude to the environment as a key attribute of the modern citizen of the world against the backdrop of the crisis in the environmental component of economic development.

Substantiation of the expediency of building a "green growth" was offered more than a quarter of a century ago. However, the need to switch to "green rails" has become especially relevant today (Pichert \& Katsikopoulos, 2008).

The historical aspects of the implementation of green growth, as well as the staged implementation of the principles of green economy in their study were submitted by such authors as Volkery and Rouabhi (2015).

Lutsko (2019), systematizing the main aspects of the concept of "green" growth, concluded that it:

- Increases the welfare of the nation.

- Allow efficient and rational use of energy resources.

- Reduces harmful emissions, protecting the environment.

- Reduces ecosystem costs and biodiversity.

After more than one scientist formed the basic principles and characteristics of green growth and greening the economy, the next step was to find ways of its development and relationalization in practice. One of these scientists was Low (2011) who in his work presented the principles of the practical development of green growth. In subsequent years, Kim, Kim, and Chae (2014) worked in this scientific field, who explored new principles for determining the level of green growth using the example of South Korea.

In recent years, these studies were continued by Pidlisnyuk, Zagirnyak, and Irkova (2020), who in their work developed strategic principles for green growth in the context of modern climate change.

In particular, Zervas (2012) and Ahlert et al. (2013) in their works investigated the influence of the latest developments in the field of green growth, in particular in the field of energy, environmental protection, in the context of landscape objects. In his work, the principles of greening the economic development of states, both at the level of an individual enterprise and at the level of the whole state, were developed.

Another scientist who studied the concept of green growth can be considered Berezhnaya (2019), who in her work systematized the international aspects of green growth, studying the experience of leading countries of the world. This work covered both research at the industry level and at the level of government.

While Vanieva (2020) explored the financial and economic instruments of green growth, which are recognized as another way to create an environmentally friendly system of government and production that offers less polluting products and services, as well as changing consumer behaviour.

Bowen (2012) investigated issues of optimizing the labour market and methods for finding new jobs in the context of implementing green growth principles.

Chmyr and Zakharkevich (2013) in his work presented the foundations of green growth in public administration. The basis of his work was the efficient use of natural resources, as well as the optimization and preservation of landscape objects.

Considering the studies presented above, we can conclude that to date, a large number of principles and measures have been developed to improve the processes of green growth both in general economic and in relations between the state and public administration. And to a greater extent, all these principles are not systematized and look like a set of optional rules and norms. Given this, an important element of our research will be the formation of a clear model that will allow us to understand the sequence of actions in achieving our goals.

\subsection{Theoretical prerequisites for methodology development}

The success of the implementation of government initiatives aimed at sustainable economic growth, to a large extent, depends on a stable understanding in the minds of people of the norm of attitude to the natural environment and social responsibility. However, even the position of "environmental indifference" has been formed over decades, can be transformed in response to transparent and effective steps by authorities in the direction of implementing the concept of sustainable development and green growth at the national level, which are accompanied by a comprehensive popularization of environmentally friendly behaviour and the idea that environmental degradation is part of economic development - the problem of every citizen, since its consequences will have a negative impact on the welfare of all excluding the inhabitants of the Earth (Kuhnhenn, 2018).

In the context of intensive globalization, integration and transnationalization of the economy, a number of problems, among which an important place belongs to the formation of an "environmentally oriented" mentality, are gaining global scale, are being updated internationally 
and are losing nationality. Accordingly, the goals of human development are also being transformed.

The concept of green growth includes the ideas of many areas of economic science, philosophy and ecology, such as environmental economics, feminist economics, postmodernism, resource-oriented economics, environmental economics, anti-consumerism, antiglobalism, green anarchism, green politics, the theory of international relations, etc. related to sustainable development and green growth problems.

The Green Growth and Sustainable Development Strategy identifies a number of key trends requiring action, as well as a number of long-term goals and specific measures at EU level to achieve them (Breitschopf et al., 2011):

- limiting climate change. The first long-term specific objective of the strategy is to limit climate change and its consequences by fulfilling the obligations of the Kyoto Protocol and the European Strategy for Climate Change. The subject of special labor is energy efficiency, renewable energy and transport;

- limiting the negative effects of transport and reducing regional differences is another long-term goal. It has been determined that it is necessary to make transport environmentally friendly and healthy. The strategy includes, inter alia, charging for infrastructure, promoting alternatives to road transport and vehicles that produce less pollution and consume less energy;

- the promotion of more sustainable modes of production and consumption. It is recognized that it is necessary to break the link between economic growth and environmental degradation and pay attention to what kind of load ecosystems can withstand. To this end, the EU should, among other things, promote green public procurement, set environmental and social performance targets for products in collaboration with stakeholders, disseminate environmental innovations and environmental technologies, and provide information and appropriate labeling of products and services;

- sustainable management of natural resources. The strategy envisages avoiding over-exploitation of natural resources, increasing the efficiency of their use through recycling, and recognizing the value of ecosystem services. In particular, the EU must make efforts in the field of agriculture, fisheries and forest management so that the Natura-2000 network is completed; identify and implement priority actions for the protection of biodiversity and ensure that due consideration is given to aspects related to the seas and oceans.

The theory of green growth is based on three axioms (O’Neill et al., 2018):

- it is impossible to infinitely expand the sphere of influence in a limited space;

- it is impossible to demand the satisfaction of infinitely growing needs in conditions of limited resources;
- everything on the surface of the earth is interconnected.

Green sectors of the economy provide for a change in the structure of the economy in which (Grubler et al., 2018):

- more attention is paid to the social aspect of sustainable development (social cohesion, ensuring access to a variety of resources, combating poverty and unemployment, etc.);

- the economy is based not only on the extractive sector, but more and more on the processing sector and the service sector;

- dominated by investments in environmentally friendly production, consumption, as well as improving the quality of goods and services from an environmental point of view;

- natural resources are used on an ongoing basis, not dependent on fossil fuels;

- forms new economic opportunities, expanding the scope of economic development and reducing poverty;

- an "ecological working system" is taking shape in agriculture, industry, in research and development, in administrative activities and in the service sector.

Now the green growth strategy is considered as a new type of strategy that operates on environmentally friendly and resource-saving and landscape-optimizing technologies and applies modern methods and techniques for implementing green development, adapting the existing production process and the way of life of society to them. The concept of green growth in its simple interpretation should be understood as a low-carbon, resource-saving, landscape-optimizing and socially inclusive model of the economy and state structure, which is developed as a more practice-oriented version of the concept of sustainable development (Prakash \& Potoski, 2006).

Since 1992, great efforts have been made by the world community to achieve sustainable development of green growth at the local, state and international levels. At the UN Millennium Forum (2000), countries agreed on a number of the Millennium Development Goals (MDGs).

\section{Methodology}

For the specification and visual modeling of ways to improve green growth in the context of government in the field of ensuring green growth and environmental safety, we have chosen a functional modeling methodology and a graphical description of the processes (IDEF0). The reason for choosing this model among others was that during its construction, the emphasis is on the phasing and characteristics of subcontracting elements of the model. In our opinion, this type of modeling itself will allow us to fully depict the sequence and conceptualism of ways to improve green growth in the context of government.

In its general theoretical form, the IDEF0 functional model is intended to describe existing processes that use both natural and graphic languages (Sylkin, et al., 2019). 
To transmit information about a particular system, the source of the graphic language is the IDEF0 methodology itself.

The IDEF0 methodology prescribes the construction of a hierarchical system of diagrams - single descriptions of fragments of the system. First, a description is made of the system as a whole and its interaction with the outside world (functional diagram), after which a functional decomposition is performed - the system is divided into subsystems and each subsystem is described separately (decomposition diagrams). Then each subsystem is divided into smaller ones and so on until the necessary degree of detail is achieved.

Blocks in IDEF0 are placed in order of importance, as the chart author understands it. This relative order is called dominance. Domination is understood as the influence that one block has on other blocks of the diagram. For example, the most dominant block of a diagram can be either the first of the required sequence of functions, planning or controlling function that affects all others.

To begin with, for the basic formation of the goal of our research, we need to create a functional diagram of the highest level A-0, which will be the main in the process of constructing a functional model IDEF0. Given this, in Figure 1, we systematized the most significant elements of modeling ways to improve the process of green growth and environmental safety in the country.
The scheme developed by us allows us to see a list of the main ways to improve the principles of green growth in the country. This hierarchical structure is a simplified model. The next step will be the use of functional mechanisms IDEF0, which will allow to expand and detail the paths to fully understand the whole algorithm of the process of improving green growth in the country.

\section{Results and discussions}

In order to fully realize the functional properties of the IDEF0 model, at this stage it is necessary to use its main feature, namely, that in this model each block implements the process of transforming inputs into outputs, while attracting certain volumes and types of resources. Given this, having formed and depicting the main goal in the form of A0, the next step in our modelling should be the formation and schematization of the initial elements that are necessary to achieve the goal in the form of a context diagram (Figure 2). The context diagram is one block with arrows that reflect the relationship of the described process with the external environment. Thus, we can say that the context diagram shows the modeling region and its boundaries. The name of the block corresponds to the name of the described function (process).

For a better understanding of the functional and systematic features of the model we constructed, it would be advisable to explain its basic elements.

A0

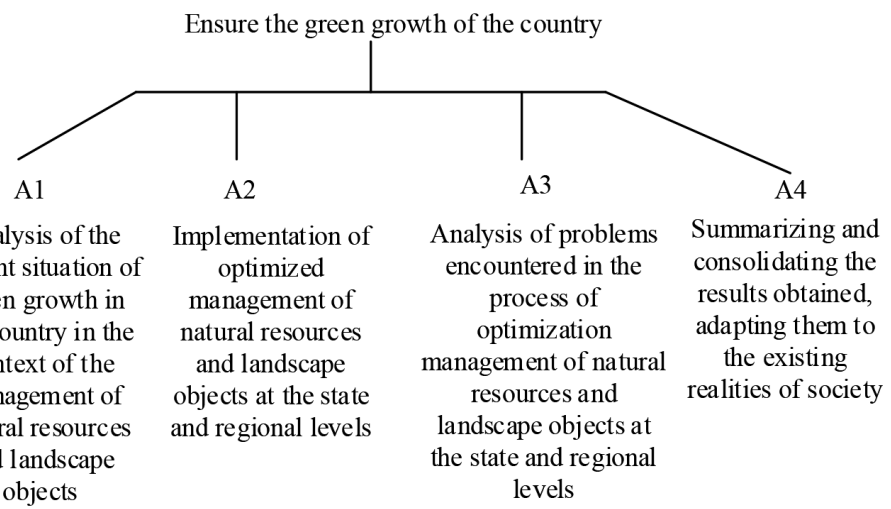

Figure 1. Hierarchical structure of functional model IDEF0 of the main ways to improve the principles of green growth in the country

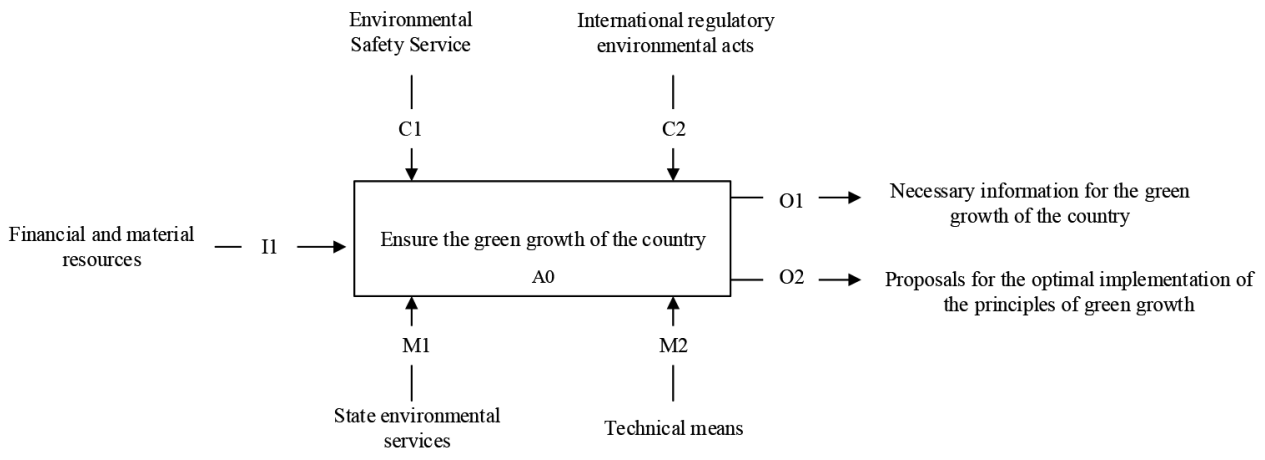

Figure 2. Context diagram of elements of model IDEF0 of the main ways to improve the principles of green growth in the country 
The input element, which is indicated by the symbol «I», in our case, means the financial and material resources necessary to achieve the goal. This group includes those resources that are already available for use, as well as those that need to be obtained in the future.

Control objects were marked as the symbol "C":

- C1 - environmental safety service. This control element forms a set of internal regulatory information that is necessary for the realization of the goal.

- C2 - international regulations, this subsection applies to the regulatory information that comes to the state from outside and forms an innovative and corrective basis for achieving the goal.

The objects of the mechanism were designated by us with the symbol "M":

- M1 - state environmental services. These objects take a more prominent place in the process of implementing the principles of green growth in the country. They determine the order, as well as the features of this process.

- M2 - technical means. Specific technical tools that are formed to implement the principles of green growth in the state are the basic mechanisms for achieving the goal, given that they are the reflection of its practical implementation.

The final elements in this process are the outputs, which reflect the result that we can get on the outputs of the practical implementation of the IDEF0 functional model. These elements are indicated by the symbol "O":

- O1 - This information is generated after all the elements of the model are completed and it becomes possible to form an assessment of the results.

- O2 - Proposals for the optimal implementation of the principles of green growth. These proposals can be formed only after a full passage of all stages, as well as after a secondary analysis and adjustment of their shortcomings and features.

After we have presented and described all the functional elements of the IDEF0 model, the next step will be the reflection of their functional interactions and interconversions. To do this, we built decompositions of the first level of the process of improving green growth processes in the state (Figure 3 ).

It is worth noting that this decomposition of the first level can be considered the initial stage. This is due to the fact that if for a better understanding of the technology and mechanisms, as well as to explain the practical implementation of this goal, it is necessary to detail the above steps, this model will allow us to build decompositions of the second, third and further levels.

Given the above decomposition, it will be useful to explain the content of each stage of the process of improving green growth in the state, in particular in public administration.

Given the decomposition presented, it would be advisable to explain the content of each of the stages of the process of improving green growth in the country, in particular in government:
- A1 - analysis of the current situation of green growth in the country in the context of the management of natural resources and landscape objects. This stage provides for the implementation of a thorough analysis of the existing situation with the subsequent identification of the most problematic areas, as well as the main prospects for the processes and mechanisms of managing natural resources and landscape objects.

- A2 - the introduction of optimized management of natural resources and landscape objects at the state and regional levels. At this stage, an attempt is made to reconcile primary measures to improve the process of green growth in the context of optimizing the public administration process. It is worth noting that this stage cannot be considered final, since after it a full assessment of the effectiveness of the measures taken should take place.

- A3 - analysis of problems arising in the process of optimizing the management of natural resources and landscape objects at the state and regional levels. During this stage, the analysis and assessment of those problems or difficulties that arose in the second stage in the process of optimizing the management of natural resources and landscape objects at the state and regional levels. In the following, based on the analysis of these problems, it will be possible to formulate and implement the necessary adjustments.

- A4 - generalization and consolidation of the results obtained, their adaptation to the existing realities of society. During this stage, the results are systematized and a holistic paradigm of the process of improving green growth in the country is formed in the context of optimizing the resource base and landscape objects. This paradigm should be characterized by flexibility and adaptability, as it should be simply implemented for different countries.

Each of these stages is a generalization of branched and complex processes. In the decomposition of the following levels, this model makes it possible to fully specify them under existing realities.

The last elements that are not described by us are intermediate inputs, outputs, control mechanisms, which are depicted in the form of arrows on the constructed functional model IDEF0. These elements consist of the following parts:

- subprocess management directives A2, A3, A4 - represent the results of the praise of the entities that control the process of monitoring the implementation of these steps;

- the output "Information on the progress of the subprocess A2, A3, A4" - represents the information that the entities responsible for the process of monitoring the implementation of these stages receive from each subprocess. Based on this information, decisions are made on the completion of subprocesses and the transition to the following.

The next steps of our study became the practical implementation of this model. It was applied in separate 


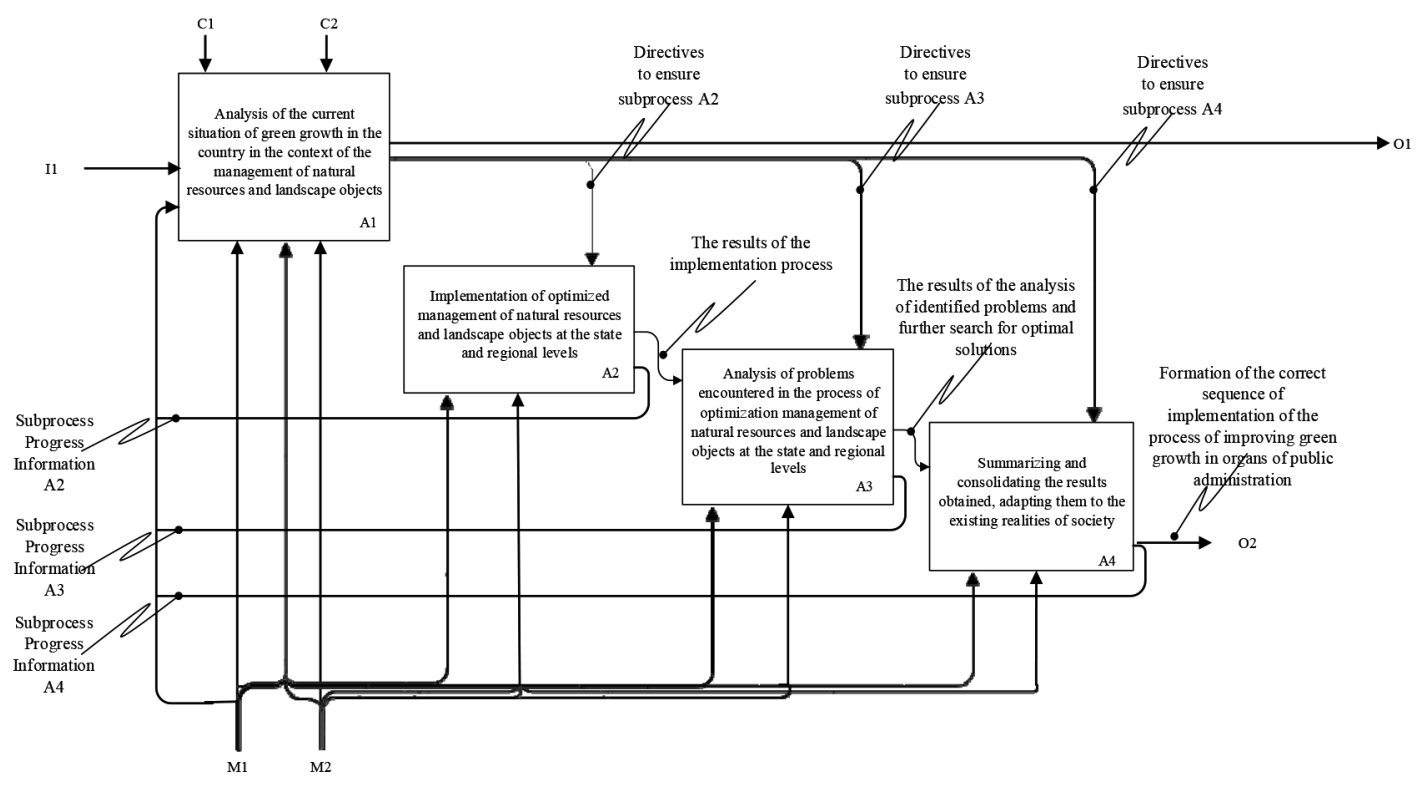

Figure 3. Decompositions of the first level of functional model IDEF0 of the main ways to improve the principles of green growth in the country

structural units of government in Eastern Europe, in particular in Poland and Ukraine.

The implementation of our proposed model took place on the example of the following structural units of public authorities in Ukraine and Poland:

In Ukraine, this model was implemented in the Lviv region in the Department of Green Development, where the model showed significant positive results in the context of explaining to ordinary employees of the department their tasks in the short and long term, which in the following led to an increase in the number of management decisions in the field of green growth.

In Poland, this model was implemented in Provincial Inspectorate of Environmental Protection in Rzeszów. In this framework, this model has also been supportive in explaining to them their operational and long-term responsibilities and objectives in the area of green growth. The use of this model had a positive impact on the number of decisions made in the field of green growth.

Participants in the practical implementation of our model were provided with questionnaires, which resulted in the identification of the number of decisions made that relate to the development of green growth in the country. The next step was to familiarize the employees of these structural units of the government with our model and suggested to use the presented steps. At the end of the practical implementation of our model, the participants were asked again to answer the questions that were asked at the beginning of the study.

After applying this model, we carried out an analysis that showed the dynamics of the effectiveness of managerial decision-making in the field of improving green growth processes.

Examples of these managerial decisions were the implementation at the regional and local levels of measures that are associated with the improvement of environmental protection mechanisms and processes of "recovery" of the economy in the context of local government. A number of decisions also concerned the introduction of measures to implement the principles of waste sorting, resource conservation and other principles of green growth in the summing-up and communal environment of cities and communities.

As a result, after conducting this analysis, we can say that the efficiency of the activities of these structural units has objectively improved, since the number of successfully implemented management decisions in the field of improving green growth has increased. These indicators are shown in Figure 4, which clearly demonstrate the effectiveness of our model.

Given the above indicators, we can conclude that the model we have formed is effective. In the future, this model can be transformed and specified for the existing realities and features of the functioning of public administration in each country

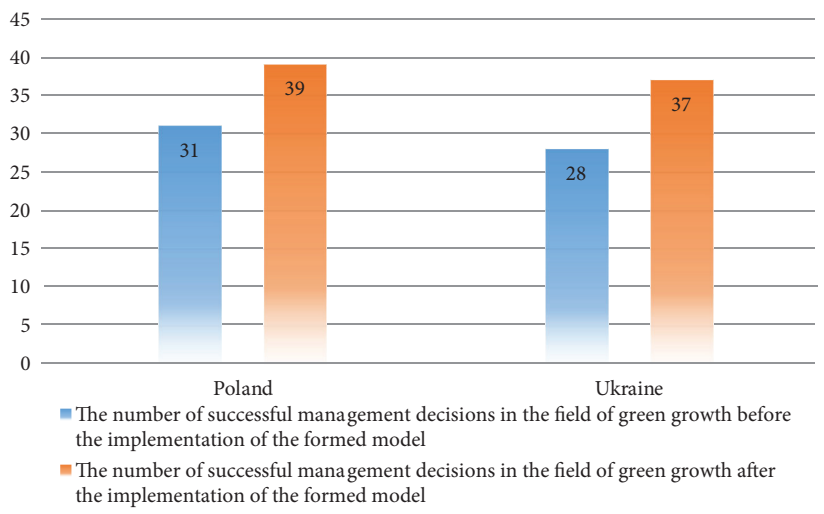

Figure 4. Dynamics of successfully implemented management decisions in the field of green growth after the implementation of our model in Poland and Ukraine 


\section{Conclusions}

Green growth means fostering economic growth and development in which natural assets continue to provide resources and environmental services. Green growth provides a practical and flexible approach to achieve concrete, measurable progress on all its economic and environmental principles, while at the same time fully taking into account the social consequences of greening the dynamics of economic growth. The focus of green growth strategies is to ensure that natural assets can fully realize their economic potential in a sustainable manner. This potential includes the provision of critical life support services - clean air and water, as well as sustainable biodiversity, necessary to maintain food production and human health. Natural assets are not infinitely replaceable, so green growth policies take this into account.

For our research, we applied the methodology of functional modeling and a graphical description of the processes (IDEF0). This model allowed us to graphically display the process of improving green growth within the country, in particular at the level of government. After the formation of all stages of this model, it was put into practice in structural units of government in Eastern Europe (Ukraine and Poland). After its implementation and analysis, it can be concluded that this model is successful and can be used in the context of improving green growth indicators in government.

The implementation of this methodology will help to preserve ecosystems, biodiversity, reduce the consumption of energy, resources, water thanks to highly efficient technologies; carbon emissions reduction; minimizing or generally preventing the formation of all forms of waste and pollution. The existing scheme makes it possible to systematize the list of basic ways to improve the principles of green growth in the country. This model is greatly simplified for better understanding. The next step in the development of green growth in a country can be the gradual detailing of the main steps of the functional model in the context of the characteristics of each individual country. The existing system of modeling ways to implement the principles of green growth using the IDEF0 methodology can further make it possible to introduce new principles of monitoring, control and protection of the environment.

\section{Author contributions}

The manuscript was written through contributions of all authors.

\section{Disclosure statement}

Authors declare that they have no competing financial, professional, or personal interests from other parties.

\section{Reference}

Ahlert, G., Meyer, B., Zieschank, R., Diefenbacher, H., \& Nutzinger, H. G. (2013). Synopsis of approaches to welfare and of green growth concepts currently under discussion (GWS Discussion Paper, No. 2013/1). GWS - Institute of Economic Structures Research, Osnabrück. https://www.econstor.eu/ bitstream/10419/94377/1/gws-paper13-1.pdf

Alrasheedi, M., Mardani, A., Mishra, A. R., Streimikiene, D., Liao, H., \& Al-nefaie, A. H. (2020). Evaluating the green growth indicators to achieve sustainable development: A novel extended interval-valued intuitionistic fuzzy-combined compromise solution approach. Sustainable Development, 29(1), 120-142. https://doi.org/10.1002/sd.2136

Arrow, K., Dasgupta, P., Goulder, L. H., Mumford, K., \& Oleson, K. (2012). Sustainability and the measurement of wealth. Environment and Development Economics, 17(3), 317-353. https://doi.org/10.1017/S1355770X12000137

Artene, A., Bunget, O.-C., Dumitrescu, A.-C., Domil, A.-E., \& Bogdan, O. (2020). Non-financial information disclosures and environmental protection - Evidence from Romania and Greece. Forests, 11(8), 814. https://doi.org/10.3390/f11080814

Berezhnaya, Yu. (2019). The concept of "green growth": International aspect. Scientific notes Tauride National University named after Vernadsky. Journal Series: Jurisprudence, 1, 210-215.

Bowen, A. (2012). "Green" growth, "green" jobs and labor markets (Working Paper). Grantham Research Institute, London, UK. http://www.lse.ac.uk/GranthamInstitute/publications/ WorkingPapers/Papers/70-79/WP76-green-growth-greenjobs-labour-markets.pdf

Breitschopf, B., Nathani, C., \& Resch, G. (2011). Methodological guidelines for estimating the employment impacts of using renewable energies for electricity generation. "Economic and Industrial Development" EID - EMPLOY, Study commissioned by IEA's Implementing Agreement on Renewable Energy Technology Deployment (IEA-RETD).

https://www.researchgate.net/publication/260434928_Methodological_guidelines_for_estimating_the_employment_impacts_of_using_renewable_energies_for_electricity_generation

Chmyr, A., \& Zakharkevich, N. (2013). Green growth: Essence, goals and basic principles. Economic Bulletin of Donbass, v3(33), 54-62.

Deschenes, O. (2010). Climate policy and labor markets (NBER Working Papers, No. 16111). National Bureau of Economic Research, Cambridge, Massachusetts.

https://doi.org/10.3386/w16111

Grubler, A., Wilson, C., Bento, N., Boza-Kiss, B., Krey, V., McCollum, D. L., Rao, N. D., Riahi, K., Rogelj, J., De Stercke, S., Cullen, J., Frank, S., Fricko, O., Guo, F., Gidden, M., Havlík, P., Huppmann, D., Kiesewetter, G., Rafaj, P., Schoepp, W., \& Valin, H. (2018). A low energy demand scenario for meeting the $1.5^{\circ} \mathrm{C}$ target and sustainable development goals without negative emissions technologies. Nature Energy, 3, 515-527. https://doi.org/10.1038/s41560-018-0172-6

Khutorova, N. (2019). Ekologicheskaya modernizatsiya - ot teorii $\mathrm{k}$ praktike [Ecological modernization - from theory to practice]. Forest Herald, 7(13), 33-40.

Kim, S. E., Kim, H., \& Chae, Y. (2014). A new approach to measuring green growth: Application to the OECD and Korea. Futures, 63, 37-48. https://doi.org/10.1016/j.futures.2014.08.002 
Kuhnhenn, K. (2018). Economic growth in mitigation scenarios: A blind spot in climate science. Heinrich Boll Foundation, Berlin. https://www.boell.de/sites/default/files/endf2_kuhnhenn_ growth_in_mitigation_scenarios.pdf

Low, L. (2011). Green growth: Implications for development planning. Climate and Development Knowledge Network, London. https://www.africaportal.org/publications/greengrowth-implications-for-development-planning/

Lutsko, V. (2019, September 23). Power, technologically ecological security and human rights. In National Conference "50 Anniversary of the General Declaration of Human Rights", (pp. 161-165). Ternopil, Ukraine.

O’Neill, D. W., Fanning, A. L., Lamb, W. F., \& Steinberger, J. K. (2018). A good life for all within planetary boundaries. Nature Sustainability, 1(2), 88-95. https://doi.org/10.1038/s41893-018-0021-4

Pichert, D., \& Katsikopoulos, K. (2008). Green defaults: Information presentation and pro-environmental behaviour. Journal of Economic Psychology, 28(1), 63-73. https://doi.org/10.1016/j.jenvp.2007.09.004

Pidlisnyuk, V., Zagirnyak, M., \& Irkova, I. (2020). Strategy for green growth and climate change. Kremenchug Publishing house "Scherbatykh".

Postuła, M., \& Radecka-Moroz, K. (2020). Fiscal policy instruments in environmental protection. Environmental Impact Assessment Review, 84, 106435. https://doi.org/10.1016/j.eiar.2020.106435

Prakash, A., \& Potoski, V. (2006). The voluntary environmentalists: Green clubs, ISO 14001, and voluntary environmental regulations. Cambridge University Press. https://doi.org/10.1017/CBO9780511617683

Sharifi, Y., Afshoon, I., Asad-Abadi, S., \& Aslani, F. (2020). Environmental protection by using waste copper slag as a coarse aggregate in self-compacting concrete. Journal of Environmental Management, 271, 111013. https://doi.org/10.1016/j.jenvman.2020.111013
Sylkin, O., Kryshtanovych, M., Zachepa, A., Bilous, S., \& Krasko, A. (2019). Modeling the process of applying anticrisis management in the system of ensuring financial security of the enterprise. Business: Theory and Practice, 20, 446-455. https://doi.org/10.3846/btp.2019.41

UN Millennium Forum. (2000) Millennium Forum adopts final declaration, action plan agenda. Press Release GA/9712. https://www.un.org/press/en/2000/20000526.ga9712.doc. html

Vanieva, A. (2020). Creation and search for promising natural resources based on secondary resources [Electronic resource]. http://www.rusnauka.com/14_ENXXI_2013/ Economics/13_136553.doc.htm

Volkery, A., \& Rouabhi, S. (2015). Green economy and sustainable development. A historical account of the discourse around sustainable development and green economy, KNOSSOS policy briefings: Green economy (Discussion Paper). UNEP, IEEP, GLOBE-EU. http://www.unep.org/research4policy/ policybriefs/tabid/78428/Default.aspx

Wellmann, T., Schug, F., Haase, D., Pflugmacher, D., \& van der Linden, S. (2020). Green growth? On the relation between population density, land use and vegetation cover fractions in a city using a 30-years Landsat time series. Landscape and Urban Planning, 202, 103857. https://doi.org/10.1016/j.landurbplan.2020.103857

Zervas, E. (2012, December 2-4). Green growth versus sustainable development. Recent Advances in Energy, Environment and Economic Development. In S. Eslamian (Ed.), Proceedings of the $3^{\text {rd }}$ International Conference on Development, Energy, Environment, Economics (DEEE '12) (pp. 399-404). Paris, France. 